\title{
Formation and specification of a Drosophila dopaminergic precursor cell
}

\author{
Joseph D. Watson and Stephen T. Crews*
}

\begin{abstract}
SUMMARY
Dopaminergic neurons play important roles in animal behavior, including motivation, reward and locomotion. The Drosophila dopaminergic $\mathrm{H}$-cell interneuron is an attractive system for studying the genetics of neural development because analysis is focused on a single neuronal cell type. Here we provide a mechanistic understanding of how MP3, the precursor to the H-cell, forms and acquires its identity. We show that the gooseberry/gooseberry-neuro (gsb/gsb- $n$ ) transcription factor genes act to specify MP3 cell fate. It is proposed that single-minded commits neuroectodermal cells to a midline fate, followed by a series of signaling events that result in the formation of a single $g s b^{+} / g s b-n^{+}$MP3 cell per segment. The wingless signaling pathway establishes a midline anterior domain by activating expression of the forkhead transcription factors sloppy paired 1 and sloppy paired 2. This is followed by hedgehog signaling that activates gsb/gsb-n expression in a subgroup of anterior cells. Finally, Notch signaling results in the selection of a single MP3, with the remaining cells becoming midline glia. In MP3, gsb/gsb- $n$ direct H-cell development, in large part by activating expression of the lethal of scute and tailup $\mathrm{H}$-cell regulatory genes. Thus, a series of signaling and transcriptional events result in the specification of a unique dopaminergic precursor cell. Additional genetic experiments indicate that the molecular mechanisms that govern MP3/H-cell development might also direct the development of non-midline dopaminergic neurons.
\end{abstract}

KEY WORDS: Cell fate, CNS midline, Dopamine, Drosophila, gooseberry, Neuron

\section{INTRODUCTION}

A key aspect of neurogenesis concerns how neural precursors are generated and acquire specific fates. The simplified view is that patterning proteins, consisting of intercellular signaling pathway components and transcription factors, activate downstream transcription factors that promote neural precursor formation and direct specific precursor fates (Skeath and Thor, 2003). The combined action of these proteins activates additional factors that control neuron-specific differentiation. Despite conceptual understanding of the factors involved, there are few in vivo examples in which the developmental progression of individual neurons has been comprehensively followed from the undifferentiated neuroectoderm to the differentiated neuron. Yet, studies of individual neurons and their precursors are particularly valuable for their detailed, mechanistic insights.

An attractive system for the systematic study of neuronal development is provided by Drosophila CNS midline cells (Fig. 1) (Wheeler et al., 2006). These cells reside between the two hemiganglia of the Drosophila ventral nerve cord (VNC). Initially consisting of 16 ectodermal cells per segment (referred to as 'mesectoderm'), these cells express single-minded ( $\mathrm{sim}$ ), which acts as a master regulator of midline cell development (Nambu et al., 1991). From this seemingly uniform set of precursor cells emerge an array of diverse interneurons, motoneurons, neurosecretory neurons, axon-ensheathing anterior midline glia (AMG) and non-ensheathing posterior midline glia (PMG) (Wheeler et al., 2006). Five of the 16 mesectodermal cells give rise

Department of Biochemistry and Biophysics, Program in Molecular Biology and Biotechnology, The University of North Carolina at Chapel Hill, Chapel Hill, NC 27599-3280, USA.

*Author for correspondence (steve_crews@unc.edu)

Accepted 21 June 2012 to midline precursors (MPs; MP1, MP3, MP4, MP5 and MP6) that divide only once to generate two neurons (Wheeler et al., 2008). MP1 divides symmetrically to generate two identical MP1 peptidergic motoneurons, MP3 divides asymmetrically into the dopaminergic (DA) H-cell and glutamatergic H-cell sib interneurons, and MP4-6 each divide asymmetrically to yield a GABAergic iVUM interneuron and a glutamatergic/ octopaminergic mVUM motoneuron. One additional midline neural precursor, the median neuroblast (MNB), is a neural stem cell that divides throughout embryonic and postembryonic development. Analysis of midline cell development has been greatly facilitated by large-scale identification of midline-expressed genes and the ability to identify each cell type at all stages of embryonic development (Kearney et al., 2004; Wheeler et al., 2006; Wheeler et al., 2008; Wheeler et al., 2009).

Recent work has focused on the development of the midline DA H-cell neuron (Stagg et al., 2011; Wheeler et al., 2008). The MP3 precursor to the $\mathrm{H}$-cell emerges during stage 11 from the mesectodermal cells (Fig. 1), rotates its spindle perpendicular to the longitudinal axis and divides asymmetrically into a basal $\mathrm{H}$-cell and an apical H-cell sib. Notch signaling is required for H-cell sib fate, but the asymmetric localization of Numb in the H-cell blocks Notch signaling, leading to its divergent fate (Wheeler et al., 2008). Both the Lethal of scute [L(1)sc] and Tailup (Tup) transcription factors are present in the H-cell (Stagg et al., 2011; Thor and Thomas, 1997). Embryos mutant for $l(1) s c$ fail to express any of the genes required for $\mathrm{H}$-cell-specific differentiation, whereas tup mutants lack expression of a subset of $\mathrm{H}$-cell differentiation genes, including pale (ple; tyrosine hydroxylase), Dopamine transporter $(D A T)$ and Dopa decarboxylase $(D d c) . l(1) s c$ is also required for the formation of MP4-6 and controls mVUM differentiation (Stagg et al., 2011). Since $l(1) s c$ function leads in one case (H-cell) to a DA fate and in the other case (mVUM) to a motoneuron fate, this suggests that the distinct identities and properties of their precursors (MP3 and MP4-6) lead to alternative neuronal fates. 


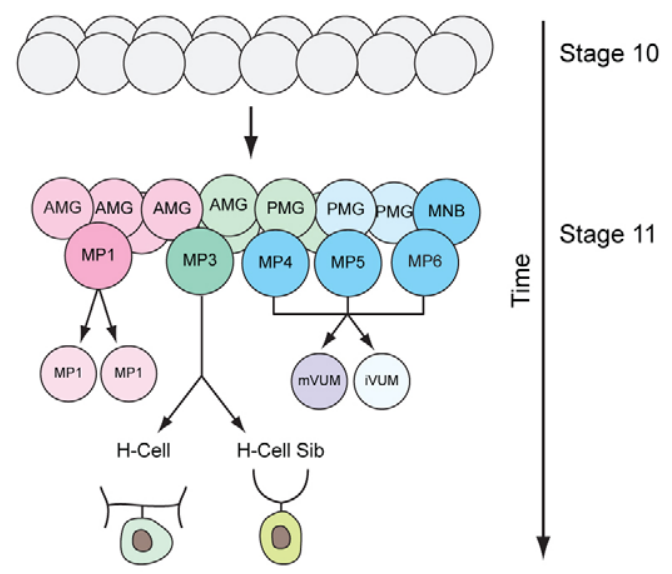

Fig. 1. Summary of Drosophila midline neurogenesis. During stages 10 to 11, 16 mesectodermal cells (gray) develop into six midline neural precursors [MP1, MP3, MP4, MP5, MP6 and the median neuroblast (MNB)] and two groups of midline glia [anterior midline glia (AMG) and posterior midline glia (PMG)]. Each MP divides once to generate two neurons.

This proposition raises several related issues: (1) what is the molecular basis of MP3 formation and MP3 identity specification; (2) how do these genes regulate $l(1) s c$ and tup to ultimately control H-cell differentiation; (3) are midline cells pre-patterned into domains permissive and non-permissive for MP3 specification; and (4) are the genes that specify MP3 development also used to control development of other Drosophila DA neuronal lineages? Here, we address the genetic mechanisms involved in MP3 formation and specification.

\section{MATERIALS AND METHODS}

\section{Drosophila strains and genetic analysis}

Drosophila mutant strains included: $D f(2 R) g s b$ (Nusslein-Volhard et al., 1984), $D f(2 R) K r 10$ (Gutjahr et al., 1993), $h h^{A C}$ (Lee et al., 1992), $p t c^{7}$ wg $^{1-12}$ (Nusslein-Volhard et al., 1984), ptc ${ }^{9}$ (Nusslein-Volhard et al., 1984), $\operatorname{slp}^{434 B}$ (Grossniklaus et al., 1992), slp1 ${ }^{2}$ (Nusslein-Volhard et al., 1984) and $w^{1-8}$ (Nusslein-Volhard et al., 1984). Mutant strains were obtained from the Bloomington Drosophila Stock Center. Gal4 and UAS lines employed were: sim-Gal4 (Xiao et al., 1996), prd-Gal4 (Xiao et al., 1996), UAS-ci.VP16 (Larsen et al., 2003), UAS-en (Guillén et al., 1995), UAS-gsb (Marie et al., 2010), UAS-gsb-n (Colomb et al., 2008), UAS-hh (Porter et al., 1996), UAS-slp1 (Sato and Tomlinson, 2007) and UAS-tau-GFP (Brand, 1995). The $p t c^{7} w g^{l-12}$ strain was grown at $29^{\circ} \mathrm{C}$ to reduce $w g$ function.

Wild-type, mutant and misexpression embryos contained sim-Gal4 UAStau-GFP in the background to assist in visualizing midline cells. Homozygous mutant embryos were identified by either: (1) staining for the absence of marked balancer TM3 P [ftz-lacZ] expression; (2) staining by in situ hybridization for lack of gene expression in deletion mutants; or (3) assaying for characteristic alterations in gene expression.

\section{In situ hybridization, immunostaining and microscopy}

Embryo collection, in situ hybridization and immunostaining were performed as previously described (Kearney et al., 2004). Embryos were commonly hybridized to two RNA probes, one labeled with digoxygenin and another with biotin, along with immunostaining with two antibodies (see http://midline.bio.unc.edu/MDB_Home.aspx, under Information>protocols). RNA probes for in situ hybridization were generated from the Drosophila Gene Collection (Open Biosystems) (en, Gad1, gsb-n, odd, ple, slp1, slp2 and VGlut) or PCR amplified from genomic DNA ( $g s b, h h$, tup). Primary antibodies used were: rat anti-Elav (1:3; Developmental Studies Hybridoma Bank), mouse anti-En (1:25)
(Patel et al., 1989), rabbit anti-GFP (1:100; Abcam), rabbit anti-Hb (1:100) (Tran and Doe, 2008), guinea pig and rat anti-L(1)sc (1:250 with TSA) (Stagg et al., 2011), guinea pig anti-Lim3 (1:250) (Broihier and Skeath, 2002), guinea pig anti-Runt (1:400 with TSA) (Kosman et al., 1998), mouse anti-Tau (1:100; Tau-2, Sigma) and guinea pig anti-Zfh1 (1:250) (Vogler and Urban, 2008). Stained embryos were imaged on Zeiss LSMPASCAL, LSM-510 and LSM-710 confocal microscopes.

\section{RESULTS}

MP3 gives rise to both the H-cell and $\mathrm{H}$-cell sib, and genes were sought that affected the development of MP3 and its progeny. Since MPs arise in defined positions along the anterior-posterior axis (Bate and Grunewald, 1981; Wheeler et al., 2008), we hypothesized that anterior-posterior patterning genes [hedgehog (hh), patched (ptc), wingless (wg), slp1, slp2, gsb, gsb- $n$, engrailed (en)] might play a role in directing MP cell fate. Eight of these genes were assayed for effects on MP3 lineage development using mutant and misexpression/overexpression approaches.

\section{gsb and gsb-n transcription factor genes specify MP3 fate}

The $g s b$ and $g s b-n$ genes are related in sequence, reside within 9.7 $\mathrm{kb}$, have similar patterns of embryonic expression and are partially redundant (Duman-Scheel et al., 1997). At stages 10-11, both gsb and $g s b-n$ are expressed in neuroectodermal stripes that are collinear with, and include, MP3 (Fig. 2A,C; supplementary material Fig. S1A,E) (Bossing and Brand, 2006). MP3 is the only $\mathrm{MP}$ in which either gene is expressed. Both genes are also expressed in the $\mathrm{H}$-cell and $\mathrm{H}$-cell sib at stage 11 (Fig. 2B,D), but are absent from all other midline neurons and MPs. Expression of both genes is absent in midline cells by late stage 12 .

The highly specific expression of $g s b$ and $g s b-n$ in MP3 and its progeny suggested that one or both of these genes play important roles in MP3 cell fate. This was initially tested using a $g s b$ gs $b-n$ double-mutant strain $[D f(2 R) g s b]$. In these experiments and throughout, midline cell identity was based on position, morphology and the use of cell-specific markers in multiply stained embryos (for examples, see Fig. 2I-N, Fig. 5B,B',E,I,J, Fig. $6 \mathrm{H}, \mathrm{N}, \mathrm{P})$. Cell fate changes were assessed by analyzing embryos at stages 14-16 for the following midline neuronal differentiation markers: H-cell (ple, tup), H-cell sib (high levels of VGlut), MP1 (Lim3, odd, Runt), iVUMs (En, Gad1) and mVUMs (Zfh1, low VGlut) (Fig. 2E-H) (Stagg et al., 2011; Wheeler et al., 2006; Wheeler et al., 2008); these data are quantitated in supplementary material Figs S2-S5.

The $D f(2 R) g s b$ embryos showed an absence of cells expressing ple (H-cell) or high VGlut (H-cell sib) and a corresponding doubling of $\mathrm{Lim}^{+}$MP1 neurons was often observed $(29 \%$ of segments scored) (Fig. 2I-K). Zfh1 ${ }^{+}$mVUM numbers also increased in $50 \%$ of $D f(2 R) g s b$ segments, most often from three to four cells (Fig. 2L). The interpretation of these findings is that $g s b / g s b-n$ are required for MP3 cell fate, and in their absence MP3 is transformed into either an MP1 or MP4-6. Since in $D f(2 R) g s b$ embryos MP3 fate is transformed rather than fails to appear, this indicates that $g s b / g s b-n$ are not required for MP3 formation or cell division. However, we note that the timing of division, as revealed by the appearance of some Tau-dense dividing cells adjacent to MP1 neurons, is delayed compared with the normal timing of the MP3 division (Fig. 2W).

The respective roles of $g s b$ and $g s b-n$ were analyzed by examining embryos homozygous mutant for only $g s b$. Since singlegene mutants for $g s b$ and $g s b-n$ are not available, we analyzed 


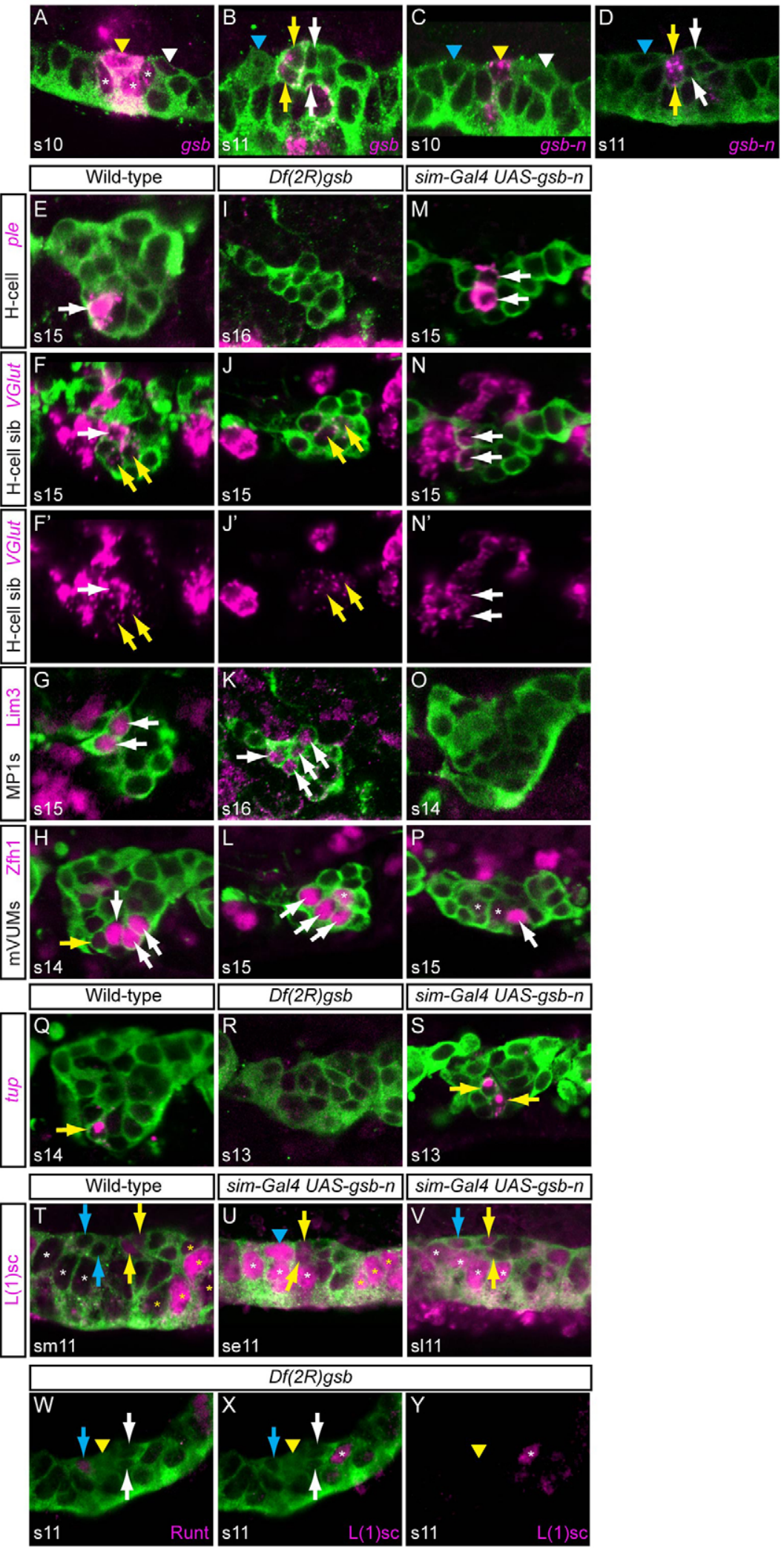

Fig. 2. gsb and gsb-n direct MP3 cell fate. All panels are sagittal views of single segments; anterior is to the left and internal up. Embryos carry sim-Gal4 UAS-tau-GFP and are stained with anti-Tau to illustrate midline cells (green), with in situ hybridization or immunostaining as indicated. (A) At stage 10, gsb RNA is present in MP3 (yellow arrowhead) and surrounding MG (asterisks), but not in MP4 (white arrowhead). (B) At stage 11, gsb is present in the $\mathrm{H}$-cell and $\mathrm{H}$-cell sib (yellow arrows) but is absent in MP1 (blue arrowhead) and mVUM4 and iVUM4 (white arrows). (C) At stage 10, gsb-n is expressed only in MP3 (yellow arrowhead), not MP1 (blue arrowhead) and MP4 (white arrowhead). (D) At stage 11, gsb- $n$ is expressed in the $\mathrm{H}$-cell and $\mathrm{H}$-cell sib (yellow arrows), but is absent from MP1 (blue arrowhead) and mVUM4 and iVUM4 (white arrows). (E-P) Stage 14-16 embryos. $\left(\mathrm{F}^{\prime}, \mathrm{J}^{\prime}, \mathrm{N}^{\prime}\right)$ Only VGlut expression is shown (compare with $\left.F_{,} J, N\right)$. (E-H) Wild-type expression of (E) ple in $\mathrm{H}$ cell (arrow), ( $\left.F_{,} F^{\prime}\right)$ high levels of VGlut in $\mathrm{H}$-cell sib (white arrow) and low levels in mVUMs (yellow arrows), (G) Lim3 in two MP1 neurons (arrows) and (H) Zfh1, which is strong in the three mVUMs (white arrows) and weak in the tup ${ }^{+} \mathrm{H}$-cell (yellow arrow). (IL) $D f(2 R) g s b$ embryos. (I) ple expression is absent. $\left(J, J^{\prime}\right)$ High VGlut expression is absent; yellow arrows indicate low VGlut mVUMs. (K) Four Lim3 ${ }^{+}$MP1 neurons are present (arrows). (L) Three $\mathrm{Zfh} 1^{+} \mathrm{mVUMs}$ are present (arrows); the additional $\mathrm{Zfh} 1^{+}$cell (asterisk) might be a fourth mVUM. (M-P) sim-Gal4 UAS-gsb-n embryos. Two ple $e^{+}$cells $(\mathrm{M})$ and two high VGlut cells $\left(\mathrm{N}, \mathrm{N}^{\prime}\right)$ are present (arrows). (O) Lim3 protein is absent. (P) Only one strong $Z \mathrm{Zhh} 1^{+} \mathrm{mVUM}$ (arrow) is present. There are two weak Zfh $1^{+}$cells (asterisks) that are ple ${ }^{+} \mathrm{H}$-cells. (Q-V) Embryos at (Q-S) stages 13-14, (T) mid stage 11 (sm11), (U) early stage 11 (se11) and (V) late stage 11 (sl11). (Q) Wild-type expression of tup in H-cell (arrow). (R) Expression of tup is absent in $D f(2 R) g s b$ embryos. (S) Misexpression of gsb-n results in two tup ${ }^{+}$cells (arrows). (T) Wild-type embryo shows L(1)sc protein in $\mathrm{H}$-cell and $\mathrm{H}$-cell sib (yellow arrows), but its absence in MP1 neurons (blue arrows) and AMG (white asterisks). $\mathrm{L}(1) \mathrm{sC}$ is also present in MP5, MP6, MNB and PMG (yellow asterisks). (U) Misexpression of gsb-n results in activation of L(1)sc in MP1 (blue arrowhead) and AMG (white asterisks). $\mathrm{H}$-cell and $\mathrm{H}$-cell sib are indicated by yellow arrows and PMG by yellow asterisks. (V) In older gsb- $n$ misexpression embryos, L(1)sc was present in MP1 neurons (blue arrow; only one neuron shown), AMG (white asterisks) and $\mathrm{H}$-cell and $\mathrm{H}$-cell sib (yellow arrows). (W-Y) Stage $11 D f(2 R) g s b$ embryo stained for (W) Runt and $(X, Y) L(1) s c$. Shown is a Runt ${ }^{+}$MP1 neuron (blue arrow), dividing MP3 (yellow arrowhead) and mVUM4 and iVUM4 (white arrows). L(1)sc is present in posterior cells but not in MP3/H-cell [compare with wild-type $\mathrm{H}$-cell and $\mathrm{H}$-cell sib L(1)sc staining in T; yellow arrows]. Note that the timing of the dividing MP3 is delayed compared with wild type (Wheeler et al., 2008).

Examination of embryos for ple and high VGlut expression indicated an absence of ple expression in $85 \%$ of segments (supplementary material Fig. S1H, Fig. S2) and an absence of high VGlut in 54\% of segments (supplementary material Fig. S1I, Fig. S3). Thus, mutant analysis indicates that $g s b$ plays a role in activating $g s b-n$ expression in MP3 and is important for MP3 transheterozygous embryos that were heterozygous for $g s b-n$ but lacked both copies of $g s b[D f(2 R) K r 10 / D f(2 R) g s b]$. Expression of $g s b-n$ was significantly reduced in the lateral CNS (supplementary material Fig. S1G, compare with S1A), as observed previously (Gutjahr et al., 1993). In the midline, $g s b-n$ was present in some segments, but absent in others (supplementary material Fig. S1G). 
lineage development. However, as $D f(2 R) K r 10 / D f(2 R) g s b$ embryos do not show as severe a phenotype as $D f(2 R) g s b$ embryos (supplementary material Figs S2, S3), both $g s b$ and $g s b-n$ are required for MP3 development.

In a complementary experiment, sim-Gal4 UAS-gsb-n embryos, in which $g s b-n$ is expressed in all midline cells at stages 10-11, showed an increase in ple $e^{+} \mathrm{H}$-cells (Fig. 2M) and high VGlut $\mathrm{H}-$ cell sibs (Fig. 2N, $\mathrm{N}^{\prime}$ ) from one to two cells per segment. Accordingly, Lim3 expression was absent (Fig. 2O), suggesting that MP1 was transformed to MP3. There was also a general decrease in VUM neurons from six to two cells, as assayed by $z \mathrm{fh} 1$ expression (Fig. 2P). However, these cells were not transformed to additional $\mathrm{H}$-cells and $\mathrm{H}$-cell sibs, so their fate is unclear. In contrast to UAS-gsb-n, misexpression of gsb (sim-Gal4 UAS-gsb) did not show an obvious effect on midline neuron cell fate (not shown). In summary, the $g s b / g s b-n$ mutant and misexpression data are consistent with $g s b-n$ and $g s b$ driving MP3 cell fate, but not its formation. Mechanistically, gsb/gsb- $n$ normally repress MP1 and MP4 fate in MP3, while also promoting MP3 fate.

The $l(1) s c$ and tup transcription factor genes are both expressed in the H-cell and control H-cell differentiation and gene expression (Fig. 2Q,T) (Stagg et al., 2011). We addressed whether their expression was controlled by $g s b / g s b-n$. H-cell expression of tup was absent in $D f(2 R) g s b$ (Fig. 2R) and misexpression of $g s b-n$ most often led to the appearance of two or more tup ${ }^{+} \mathrm{H}$-cells in
28/38 segments scored (Fig. 2S). Similarly, $l(1) s c$ expression was absent from the H-cell in $D f(2 R) g s b$ mutants (Fig. $2 \mathrm{~W}-\mathrm{Y}$ ), and $g s b$ $n$ misexpression resulted in a strong increase in $l(1) s c$ expression in MP1 neurons and AMG (Fig. 2U,V). These results indicate that $g s b / g s b-n$ (directly or indirectly) regulate the expression of tup and l(1)sc.

\section{s/p1/2 establish a permissive anterior midline domain for MP3 and MP1 cell fates}

Having established that $g s b / g s b-n$ control MP3 cell fate, the next issue concerns how gsb/gsb- $n$ expression is activated in the midline cells. The first developmental event involves establishing an anterior midline domain, compatible with the formation of MP3. This hypothesis is based on the observation that ectopic gsb- $n$ most often generates a single additional MP3 at the expense of the more anterior MP1 or adjacent MP4; it does not generally convert more posterior MPs (MP5 and MP6) and the MNB to MP3. We analyzed the role of $s l p 1$ and $s l p 2$, which are closely related in sequence, reside within $9.7 \mathrm{~kb}$, have similar expression patterns and genetically have largely redundant segmentation phenotypes (Cadigan et al., 1994). At stage 9, both genes are expressed in mesectodermal rows D-F, which are adjacent to, but do not overlap with, the en expression domain (rows G,H) (Wheeler et al., 2006). Rows D-F are likely to give rise to MP3. At stage 10, both genes are expressed in anterior midline cells, including MP1, MP3 and

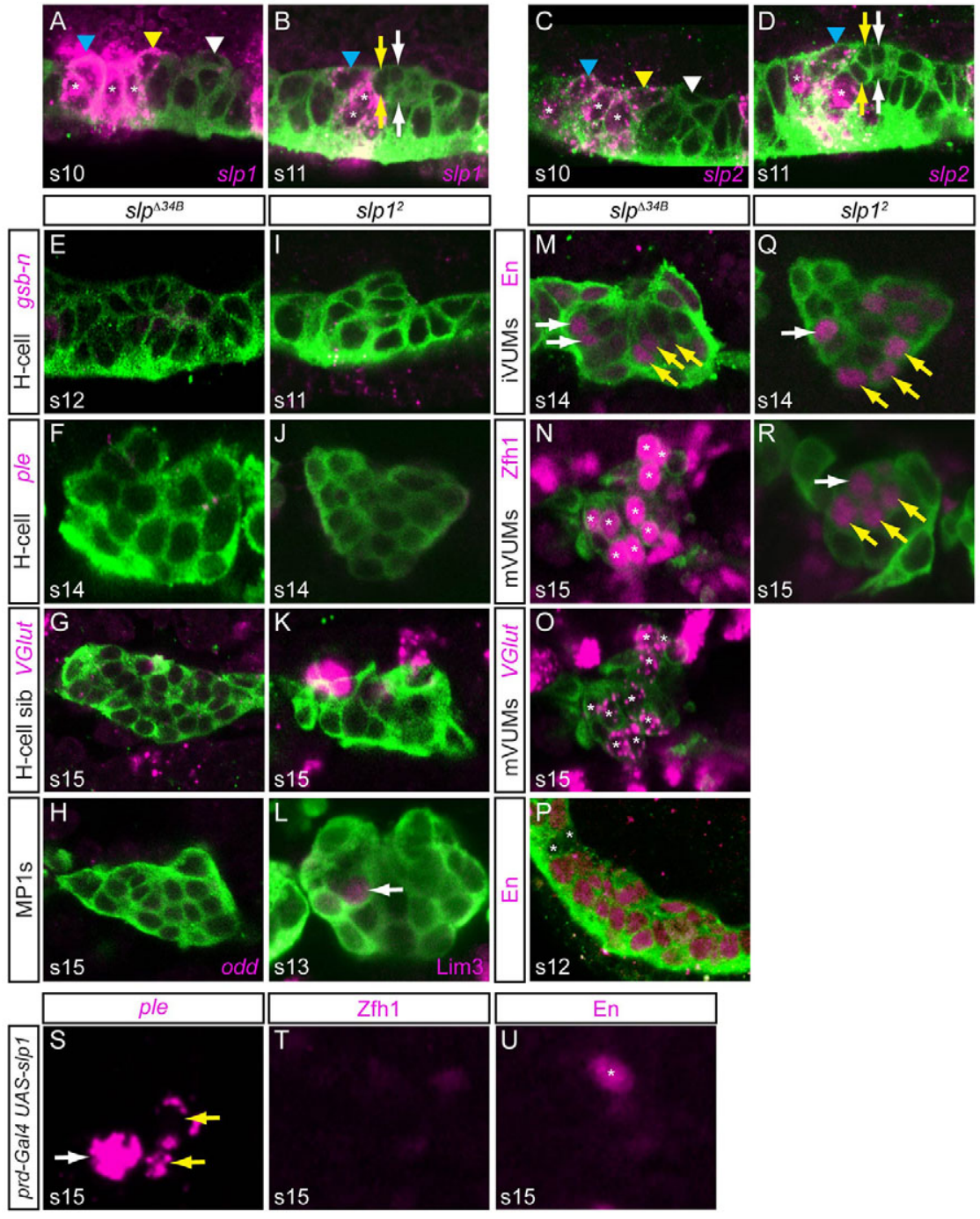

Fig. 3. s/p1/2 establish an MP3/MP1 permissive region in anterior midline cells. $(\mathbf{A}, \mathbf{C})$ At stage 10, s/p1 and s/p2 are expressed in MP1 (blue arrowhead), MP3 (yellow arrowhead), AMG (asterisks), but not MP4 (white arrowhead). (B,D) At stage 11, s/p1 and s/p2 expression is present in MP1 (blue arrowhead) and some AMG (asterisks), but absent in $\mathrm{H}$-cell and $\mathrm{H}$-cell sib (yellow arrows) and iVUM4 and mVUM4 (white arrows). (E-H) In s/p $p^{434 B}$ embryos, H-cell (gsb-n, ple), H-cell sib (high VGlut) and MP1 (odd) gene expression is absent. (M) En is present in multiple anterior midline neurons (white arrows) in addition to the three iVUMs (yellow arrows).

$(\mathbf{N}, \mathbf{O})$ Additional Zfh $1^{+}$( $\mathrm{N}$, asterisks) and low VGlut $\left(\mathrm{O}\right.$, asterisks) neurons are present in $s / p^{\Delta 34 B}$ in addition to the three mVUMs (also asterisks). (P) At stage 12, En expands into most midline cells in $s / p^{434 B}$ embryos. In this segment, two glia (asterisks) and four neurons (not shown) were $\mathrm{En}^{-}$ (I-K) s/p1 mutant $\left(s / p 1^{2}\right)$ had reductions in gsb-n, ple and VGlut expression. (L) Lim3 protein was weakly present (arrows) in $s / p 1^{2}$. $(\mathbf{Q}, \mathbf{R})$ There is an extra En ${ }^{+}$cell $\left(\mathrm{Q}\right.$, white arrow) and $\mathrm{Zfh} 1^{+}$cell $(\mathrm{R}$, white arrow) in anterior midline cells in s/p $1^{2}$ embryos at the position of MP1 neurons. Yellow arrows mark (Q) iVUMs and (R) mVUMs.

(S-U) Stage 15 prd-Gal4 UAS-s/p1 embryos were stained for (S) ple, (T) Zfh1 and (U) En. Multiple ple $e^{+}$cells (yellow arrows) were observed posterior to the $\mathrm{H}$-cell (white arrow), whereas no Zfh $1^{+}$ mVUMs or En+ ${ }^{+}$iVUMs were observed. (U) The $\mathrm{En}^{+}$ cell (asterisk) is either MNB progeny or PMG. 
AMG (Fig. 3A,C; supplementary material Fig. S1B,F). However, after MP3 divides during stage 11, expression of both slp1 and slp2 is absent from the H-cell and H-cell sib (Fig. 3B,D). Thus, slpl and slp2 overlap in expression in the midline cells from which MP3 will form.

The potential role of $\operatorname{slp} 1$ and $\operatorname{slp} 2$ in midline cell development was tested by genetic analysis using an slp1 slp2 double-null strain $\left(s l p^{\Delta 34 B}\right)$ and an $\operatorname{slp} 1$ null mutant strain $\left(s l p 1^{2}\right)$. In $s l p^{434 B}$ embryos, MP3 and H-cell gsb- $n$ expression was absent at stages 10-12 (Fig. $3 \mathrm{E})$, and $\mathrm{H}$-cell ple and tup expression and H-cell sib high VGlut expression (Fig. 3F,G; tup not shown) were absent at later stages. MP1 neuronal odd expression was also absent in $s p^{\Delta 34 B}$ embryos at stages 12 and 13 (Fig. 3H). Thus, MP3 and MP1 progeny were absent. There was a corresponding increase in MP4-6 VUM progeny, as indicated by additional $\mathrm{En}^{+}$iVUMs and $\mathrm{Zfh}^{+}$low VGlut mVUMs (Fig. 3M-O). Examination of earlier, stage 12 mutant embryos indicated that En expanded throughout most of the segment (Fig. 3P). This result reinforces the view that $s l p 1 / 2$ repress posterior gene expression in anterior cells. Similar results were observed for the $\operatorname{slp} 1^{2}$ single mutant, except that the effects were weaker (Fig. 3I-L,Q,R), suggesting that slp1 and slp2 act redundantly. Together, these results indicate that $s l p 1 / 2$ are required for MP1 and MP3 fates and repress MP4-6 fates in both MP3 and MP1.

The $\operatorname{slp} 1 / 2$ mutant results suggested that misexpressing slp $1 / 2$ in all midline cells might convert MP4-6 to MP3 or MP1. Whereas sim-Gal4 UAS-slp1 embryos were unaffected in midline cell fates (data not shown), when we expressed slp1 earlier using prd-Gal4 we observed an increase in the number of $p^{+} e^{+}$cells at the expense of $\mathrm{Zfh}^{+}$mVUMs and $\mathrm{En}^{+}$iVUMs (Fig. 3S-U). These results reinforce the $s l p 1 / 2$ mutant results and indicate that $s l p 1 / 2$ influence MP3 and MP1 fate by establishing a permissive anterior midline environment at stages 9-10 for specification of MP1 and MP3 identity. slp1/2 might accomplish this by repressing genes, including en, that, if expressed in these cells, would shift them toward posterior midline MP4-6 fates.

\section{Mutants in wg activate s/p1/2 expression and MP3 fate}

The next issue concerns how the $\operatorname{slp} 1 / 2$ anterior domain is established. Previous work has shown that $\mathrm{wg}$ can induce $\operatorname{slp} 1 / 2$ expression in other cell types (Bhat et al., 2000) and $w g$ can influence midline gene expression (Bossing and Brand, 2006). Consequently, we addressed whether $w g$ signaling influences slp1/2 expression and MP3 development. wg encodes a secreted signaling protein, and at stage 9 it is expressed in a stripe, including midline cell rows $\mathrm{E}$ and $\mathrm{F}$, that spans the neuroectoderm (supplementary material Fig. S1C) (Wheeler et al., 2006; Xiao et al., 1996). Expression of $w g$ is absent from the midline at stages 10-11, but remains in the lateral stripe adjacent to the midline.

Analysis of $w g$ null mutant $\left(w g^{1-8}\right)$ embryos indicates a strong reduction of $g s b-n$, ple, tup and of high VGlut expression (Fig. 4AD), consistent with a loss of MP3. There was a mild reduction in the number of MP1 neurons, with $25 \%$ of segments possessing no MP1 neurons (Fig. 4E) and 75\% of segments with the wild-type number of two neurons. VUMs were relatively unaffected, although one to two additional $\mathrm{Zfh} 1^{+}$cells were observed in $61 \%$ of segments (Fig. 4F). Of particular note is that slp1 expression was absent from the midline in $w g$ mutant embryos (Fig. 4G). In summary, these data suggest a model in which $w g$ activates $s l p 1 / 2$ in an anterior midline domain, thus allowing MP1 and MP3 to form.

\section{Ectopic en alters MP3 and MP1 fates}

One potential role of $s l p 1 / 2$ is to repress posterior gene expression in the anterior midline cells. A strong candidate is en, the posterior expression of which is adjacent to, but does not overlap with, slp1/2 expression (supplementary material Fig. S1B,F). At stage 9, en is expressed in a stripe that includes midline rows $\mathrm{G}$ and $\mathrm{H}$ and is collinear with the lateral ectodermal stripe (Kearney et al., 2004). Expression of en at stage 10 is present in two MG that lie between the MP3 and MP4 neural precursors (Fig. 5A) (Watson et al., 2011). At stage 11, en expands into MP4, MP5, MP6, MNB and all PMG (Fig. 5B) (Wheeler et al., 2006). Most importantly, en is not expressed in MP1, MP3, H-cell or H-cell sib (Fig. 5B'). Later, at stage 15, En is prominently expressed in the three iVUM neurons (Fig. 5C).

Analysis of $s l p 1 / 2$ mutant and $\operatorname{slpl}$ misexpression embryos indicates that they repress en (Fig. 3M,P,Q,U), and possibly other genes, in anterior midline cells. This suggests that if en is present in MP3 its fate might be altered. This was addressed by misexpressing en in MP3 and MP1 in sim-Gal4 UAS-en embryos. The expression of $g s b-n$ in MP3 was not significantly affected (Fig. $5 \mathrm{D})$, indicating that the presence of en did not block activation of $g s b-n$. However, ectopic en resulted in a decrease of ple, tup (both H-cell), high VGlut (H-cell sib) and Lim3 (MP1) expression (Fig. $5 \mathrm{E}-\mathrm{H})$. There was a small increase in $\mathrm{Zfh} 1^{+}$mVUMs (3.4 \pm 0.5 ; Fig. 5I) and $\mathrm{Gadl}^{+}$iVUMs (3.6 \pm 0.6 ; Fig. 5J) compared with wild type (3.0 cells). The additional VUM cells were usually the anteriormost neurons at the position of MP1 neurons. By contrast, neurons at the position of H-cell and H-cell sib (Fig. 5I,J, asterisks) generally did not express any midline neuron marker, although occasionally low levels of ple were present. This suggests that the presence of en in the $\mathrm{H}$-cell and $\mathrm{H}$-cell sib alters their neuronal identity, but does not

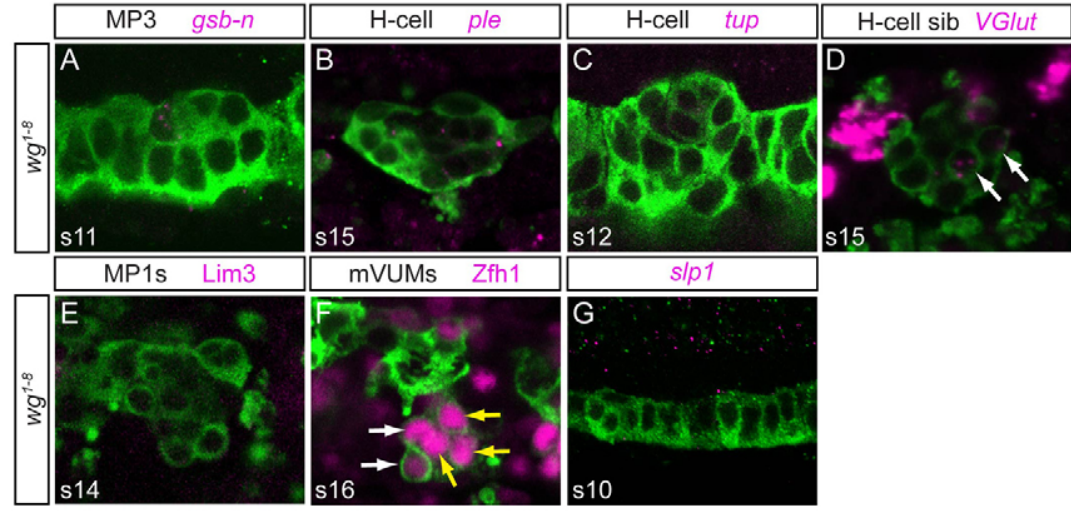

Fig. 4. wg signaling influences $s / p 1 / 2$ expression. (A-E) In $w g^{1-8}$ embryos, expression of gsb-n, ple, tup, high VGlut and Lim3 was strongly reduced. The weak midline VGlut staining ( $D$, arrows) is from mVUMs. (F) Additional Zfh $1^{+}$cells (white arrows) were often observed in $w^{1-8}$ embryos (mVUMs, yellow arrows). (G) Expression of $\operatorname{slp} 1$ was absent in $w^{1-8}$. 

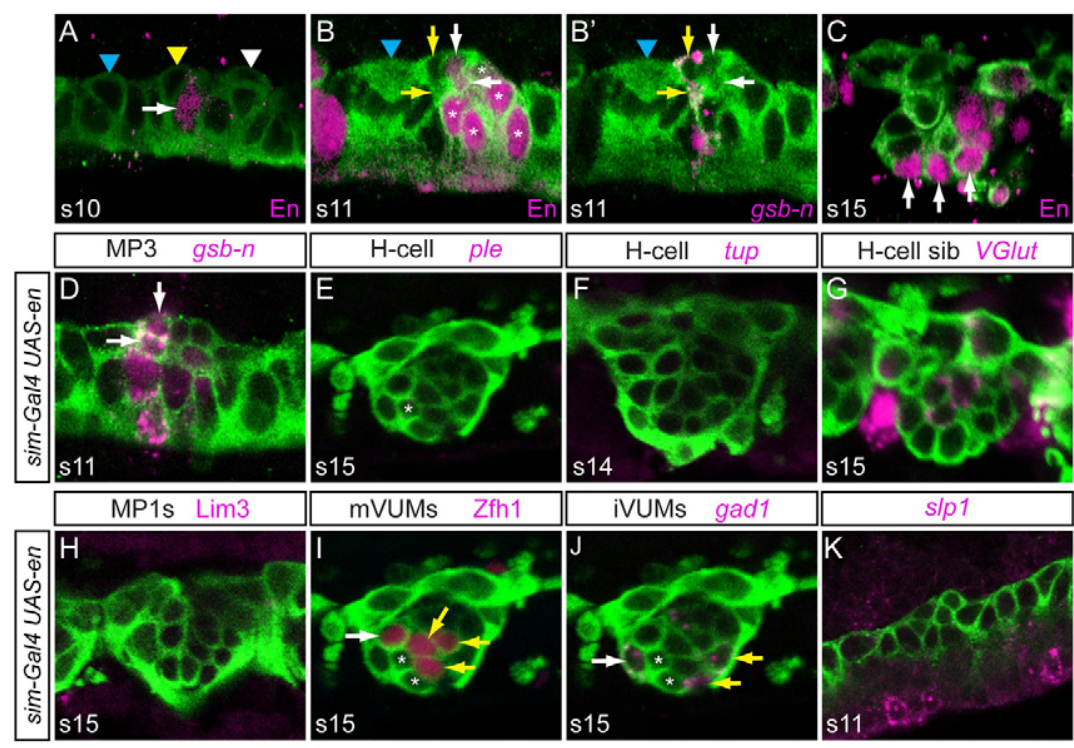

Fig. 5. Ectopic en alters MP1 and MP3 cell fate. (A) At stage 10, En is present in only two MG cells (arrow; only one cell is shown). En is absent from all neural precursors, including MP1 (blue arrowhead), MP3 (yellow arrowhead) and MP4 (white arrowhead). (B, $\mathbf{B}^{\prime}$ ) At stage 11, En defines the posterior midline cells. The same segment is shown stained for (B) En and ( $\left.\mathrm{B}^{\prime}\right)$ gsb- $n$. (B) En is present in VUM4 progeny (white arrows) and MP5, MP6, MNB and PMG (asterisks). En is absent from H-cell and $\mathrm{H}$-cell sib (yellow arrows), which are both gsb- $n^{+}\left(\mathrm{B}^{\prime}\right)$, and En is also absent in MP1 (blue arrowheads). (C) At stage 15, En is present in the three iVUM4-6 neurons (arrows). (D-H) In stage 11 sim-Gal4 UAS-en embryos, gsb-n expression in $\mathrm{H}$-cell and $\mathrm{H}$-cell sib (arrows) was unaffected (D) and expression of ple, tup, high VGlut and lim3 was greatly reduced (E-H). Low levels of ple could be detected in a single cell (asterisk), indicating that it is likely to be an H-cell. (I,J) Additional Zfh $1^{+}$and Gad $1^{+}$cells are present in the position of MP1 neurons (white arrows) in sim-Gal4 UAS-en embryos. Yellow arrows indicate (I) mVUMs and (J) iVUMs, and probable H-cell and Hcell sib are indicated by asterisks (see E). (K) Absence of s/p1 midline expression in a stage $11 \mathrm{sim}$-Gal4 UAS-en embryo.

transform these cells into VUMs; MP1s might be more permissive to VUM transformation by en.

Ectopic en also resulted in an absence of slp1 from midline cells (Fig. 5K). Since slp1/2 repress en, these results indicate that en and slp 1/2 mutually repress each other. If $e n$ is expressed in MP1 and MP3 it can alter their fates and thus it is important to restrict its expression, which is a function of $\operatorname{slp} 1 / 2$. These results also indicate that misexpressed en has the ability to drive MP1 cells into an MP4-6 fate or that en interferes with the establishment of MP1 fate leading to a default state resembling MP4-6.

\section{MP3 fate is dependent on $\boldsymbol{h} h$ signaling}

$s l p 1 / 2$, activated by $w g$, establish an anterior domain that is necessary for the expression of $g s b-n$ in MP3. However, we propose that $w g$ and $s l p 1 / 2$ commit anterior midline cells to an MP1 fate and that an additional factor is required to commit a group of those cells to an MP3 fate. An attractive candidate for this factor is $\mathrm{Hh}$, a prominent secreted signaling protein that directs alternative MG fates (Watson et al., 2011). At stages 10-11, hh is largely absent from the midline, but is expressed as a stripe in the lateral neuroectoderm (supplementary material Fig. S1D). We addressed whether $h h$ signaling plays a role in MP3 cell fate.

Initially, elav expression was examined at stages 12-14 in $\mathrm{hh}$ mutants to assess whether $h h$ affects midline neuronal cell number (Robinow and White, 1991). Segments contained 4.2 $\pm 1.1 \mathrm{Elav}^{+}$ cells, whereas wild-type embryos contained 12.0 neurons at these stages (Fig. 6A,B; supplementary material Fig. S6A). However, $72 \%$ of embryos contained either four $(46 \%)$ or six $(26 \%)$ neurons. These data indicate that $h h$ is required for the production of many midline neurons. Staining with neuron-specific markers indicated that when four or six neurons were present in $h h$ null mutant $\left(h h^{A C}\right)$ embryos, they comprised two MP1 neurons (the progeny of a single MP1 precursor), one to two mVUMs and one to two iVUMs (Fig. 6G,I,K; supplementary material Fig. S6B-D; stages 12-14). By contrast, H-cell (Fig. 6M), H-cell sib (Fig. 6O), one to two iVUMs, one to two mVUMs, and the MNB and its progeny were absent. Consistent with the absence of $\mathrm{H}$-cell and $\mathrm{H}$-cell sib gene expression, gsb- $n$ expression was absent at stages 10-11 (Fig. 6Q) in the midline of $h h^{A C}$ embryos. As expected, tup was also absent (Fig. 6S) at stage 11 and later, and L(1)sc staining was absent in the midline of $h h^{A C}$ stage 11 embryos (Fig. 6U). The presence of only four to six neurons in $h h^{A C}$ embryos indicates that, generally, one or two of three MP4- 6 cells and the MNB require $h h$ signaling for formation. Surprisingly, the slp1 expression domain is increased in some segments in $h h$ mutant embryos at stages 10-11, although levels are reduced compared with wild type (Fig. 6C-F). This suggests that $h h$ signaling helps in maintaining a sharp boundary of $s l p 1 / 2$ expression. Despite this expansion of $s l p 1 / 2, h h$ mutants fail to generate an MP3 or additional MP1s. Thus, we hypothesize that $h h$ signaling plays three roles in midline neuronal development: (1) a proneural role for MPs and the MNB; (2) a role in specifying MP3 cell fate; and (3) a role in restricting slp1/2 expression to anterior midline cells.

Consistent with the $h h$ MP3 cell fate mutant phenotype, overactivation of $h h$ signaling in all midline cells resulted in an increase in MP3s. ptc encodes an Hh receptor that, in the absence of $h h$ signaling, inhibits the ability of Smoothened (Smo) to activate the $h h$ signaling pathway (Ingham and McMahon, 2001). When activated by $\mathrm{Hh}$, Smo is released from Ptc inhibition. Thus, ptc expression is present in cells responding to $h h$ signaling, and $p t c$ mutants act as constitutive activators of $h h$ signaling. At stage 10 , ptc is expressed in most midline cells, including all MPs, with the exception of two $\mathrm{en}^{+}$MG that lie between MP3 and MP4 (Watson et al., 2011). Most striking are the high levels of ptc in 

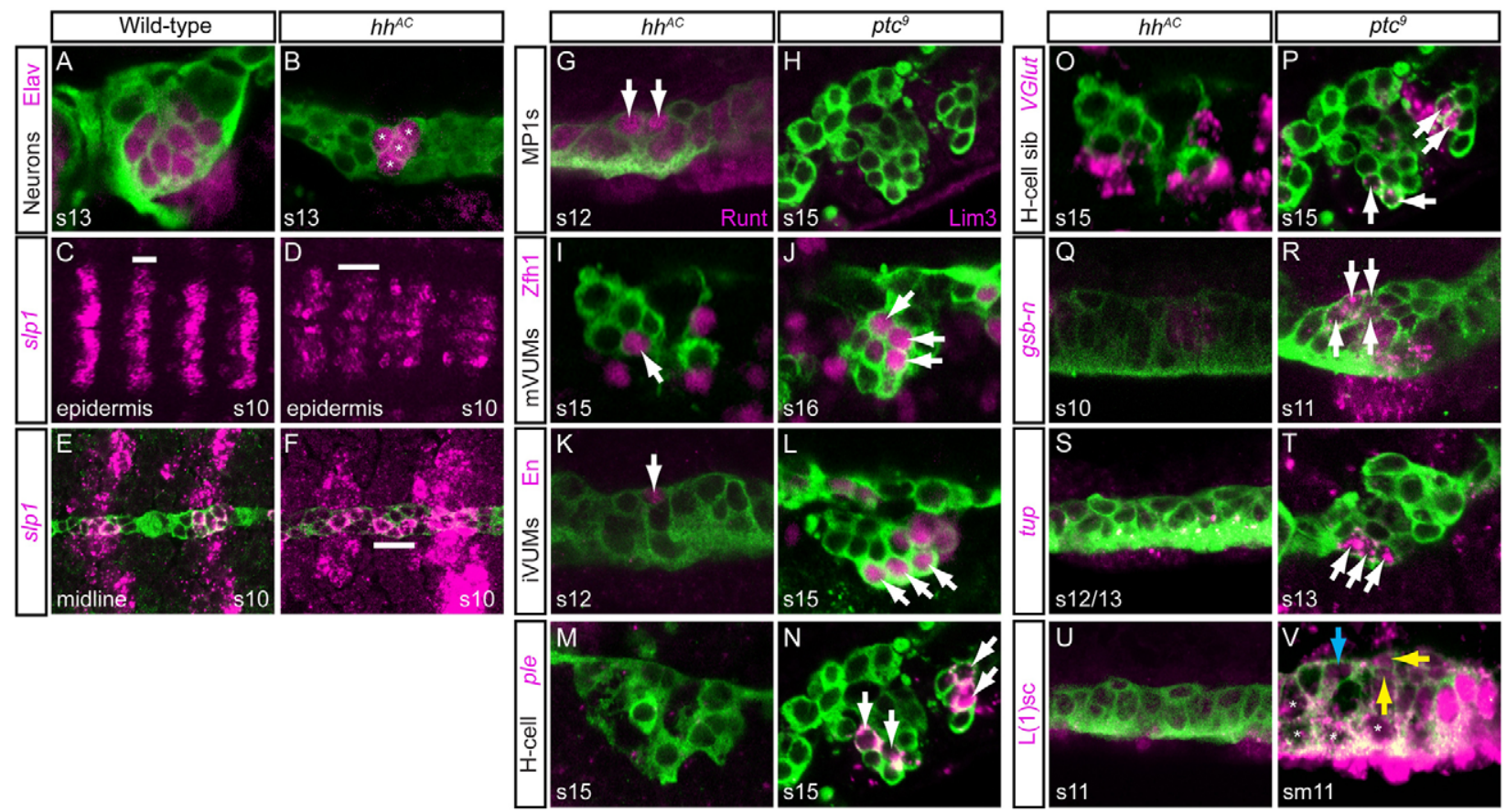

Fig. 6. $\boldsymbol{h}$ h signaling is required for MP3 formation and identity. Analyses of sim-Ga/4 UAStau-GFP embryos are shown. (A) This wild-type embryo had 11 Elav $^{+}$neurons (eight are shown). (B) This $h h^{A C}$ embryo had six Elav ${ }^{+}$neurons (asterisks marksfour). (C,D) s/p1 expression was expanded in the epidermis of $h h^{A C}$ mutants [compare the width of the white bar in wild-type (C) and mutant (D)]. (E,F) s/p1 expression was expanded (white bar) in midline cells in $h h^{A C}$. (G) In $h h^{A C}$ mutants, two Runt ${ }^{+}$MP1 neurons (arrows) were present, as in wild type. (I,K) $h h^{A C}$ embryos possessed only (I) one Zfh1+ mVUM and (K) one En+ iVUM (arrows). (M, $\mathbf{O}, \mathbf{Q}, \mathbf{S}, \mathbf{U})$ In $h h^{A C}$ mutants, there was an absence of (M) ple, (O) high VGlut, (Q) gsb-n, (S) tup and (U) I(1)sc expression. $(\mathbf{H}, \mathbf{J}, \mathbf{L})$ ptc ${ }^{9}$ mutants had an absence of Lim3 (H), but a wild-type number of three mVUMs $(\mathrm{J})$ and three iVUMs (L) (arrows). (N,P) ptc ${ }^{9}$ mutant had additional (N) ple ${ }^{+}$and (P) high VGlut cells (arrows); two segments are shown. (R) Stage 11 $p t c^{9}$ embryo had four gsb- $n^{+}$cells (arrows). ( $\left.\mathbf{T}\right)$ tup is ectopically expressed in a ptc ${ }^{9}$ mutant in three cells (arrows). (V) In ptc ${ }^{9}, \mathrm{~L}(1) s c$ is ectopically present in MP1 neurons (blue arrow; only one MP1 neuron is shown), as well as in the H-cell and H-cell sib (yellow arrows) and AMG (white asterisks)

MP3 (Watson et al., 2011). In a ptc null mutant ( $\left.p t c^{9}\right)$ there were commonly two ple ${ }^{+} \mathrm{H}$-cells (Fig. 6N) and two high VGlut $\mathrm{H}$-cell sibs (Fig. 6P). MP1 marker gene expression was absent (Fig. 6H), whereas iVUM and mVUM marker expression resembled that of wild type (Fig. 6J,L). There was also an increase in $g s b-n^{+}$neurons (H-cell and H-cell sib) in $p t c^{9}$ (Fig. 6R), further indicating that $h h$ activates $g s b / g s b-n$ expression in MP3. Consistent with this result, an increase in L(1)sc levels and tup ${ }^{+}$cells also occurred in ptc mutant embryos (Fig. 6T,V). Similar results to the $p t c^{9}$ mutant were observed for sim-Gal4 UAS-hh embryos, which overexpress $h h$ in midline cells (supplementary material Figs S2-S5).

One issue regarding the $h h$ and ptc mutant and $h h$ overexpression experiments is whether the effects of $h h$ are due to alterations in ectodermal patterning and are not autonomous to midline cells. This was addressed by examining sim-Gal4 UAS$c i . V P 16$, in which the $h h$ signaling pathway is only active in midline cells ( $c i$ encodes the transcriptional effector of the $h h$ signaling pathway). These experiments also showed an increase in $\mathrm{H}$-cell and H-cell sib at the expense of MP1 (supplementary material Figs S2-S4).

Since the $h h$ and $w g$ signaling pathways are known to regulate each other (Hatini and DiNardo, 2001) it is possible that the wg MP3/H-cell phenotype only reflects a reduction in $h h$ signaling and is not due to a direct effect of $w g$. To address this issue, ptc wg double-mutant embryos were examined, as they lack $w g$ function but have constitutively active $h h$ signaling. The results showed that expression of $g s b-n$, odd, ple and slpl was absent (supplementary material Fig. S7A,B,D,G), whereas $z f h 1$ mVUM expression and en iVUM expression were expanded (supplementary material Fig. $\mathrm{S} 7 \mathrm{C}, \mathrm{E}, \mathrm{F})$. Thus, $w g$ is required for $g s b-n$ MP3 expression. Similarly, the ability of activated $h h$ in anterior midline cells to generate additional $g s b-n^{+} \mathrm{MP} 3 \mathrm{~s}$ via sim-Gal4 UAS-Ci.VP16 indicates that $h h$ can activate $g s b-n$ expression. In summary, the $h h$ mutant and misexpression experiments demonstrate that $h h$ signaling emanating from outside the midline is directly responsible for MP3 cell fate. When overexpressed, $h h$ signaling has the ability to convert MP1 into MP3, indicating that MP1 and MP3 derive from a developmentally similar ground state.

\section{Genes controlling MP3 development are also required for the development of other Drosophila dopaminergic neurons}

We have demonstrated that $g s b / g s b-n, h h / p t c, w g$ and $s l p 1 / 2$ are required for $\mathrm{MP} 3 / \mathrm{H}$-cell development. Do these genes also control the development of DA neurons in other lineages? In the embryonic VNC, two additional DA neurons exist per hemisegment in addition to the H-cell (Lundell and Hirsh, 1994). These are the paramedial DA neurons and dorsal lateral DA neurons (Fig. 7A). Interestingly, most of these neurons are collinear with the $\mathrm{H}$-cell suggesting that the same segmentation genes that control H-cell development also play a role in paramedial and dorsal lateral neuron development. Consistent with this view, recent work (Tio et al., 2011) has indicated that both DA neurons are $w^{+}$, which overlaps in lateral CNS expression with gsb and $s l p 1 / 2$ 


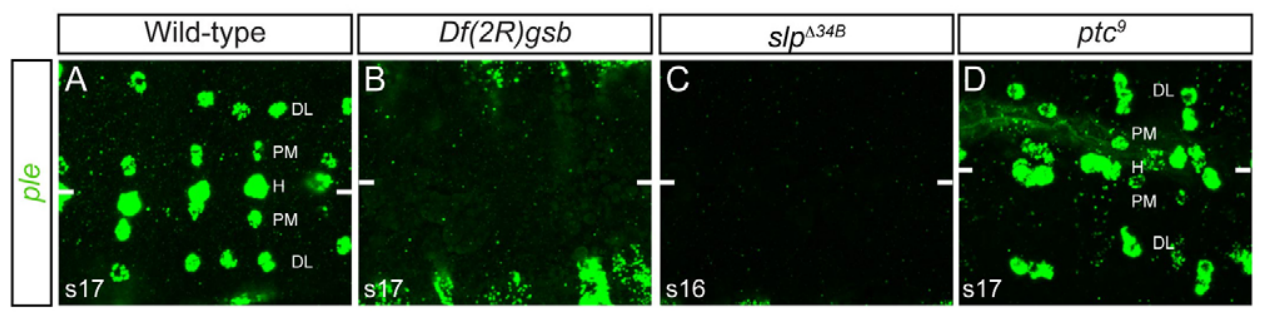

Fig. 7. Genes controlling H-cell development also affect non-midline DA neuronal development. Horizontal views of the CNS of stage 14$16 \mathrm{sim}$-Gal4 UAS-tau-GFP embryos stained for ple expression. (A) Wild-type embryo showing the ventral nerve cord (VNC) of dopaminergic (DA) neurons: H-cell $(H)$, paramedial DA neurons $(M)$ and dorsal lateral DA neurons (DL). (B-D) DA neuron ple expression was absent from $D f(2 R) g s b(B)$ and $s / p^{\Delta 34 B}(C)$ but expanded in $p t c^{9}(D)$. The ple staining in $B$ is in epidermal stripes. White bars indicate the midline.

(supplementary material Fig. S1A-C,E,F). We looked at ple expression in the paramedial DA and dorsal lateral DA neurons in $D f(2 R) g s b, p t c^{9}$ and $s l p^{\Delta 34 B}$ embryos at stage 16 . In $D f(2 R) g s b$ and $s^{434 B}$ embryos (Fig. 7B,C) ple expression was absent in all lateral DA neurons. In $p t c^{9}$ embryos (Fig. 7D) there were additional ple $e^{+}$ dorsal lateral neurons in $57 \%$ of hemisegments scored $(n=42)$ and additional paramedial DA neurons in $52 \%$ of hemisegments $(n=50)$. These results are similar to the effects seen on the H-cell and provide an initial indication that different Drosophila DA neurons might share a common set of genes for their development.

\section{DISCUSSION}

The results presented here and in the literature (Stagg et al., 2011; Wheeler et al., 2008) have identified key regulators of Drosophila MP3/H-cell development, as summarized in Fig. 8.

\section{sim and the functional role of master regulatory genes}

The Drosophila sim gene is a master regulator of CNS midline cell development. sim mutants fail to develop midline neuronal and glial precursors, and midline transcription of almost all genes normally expressed in the midline is absent (Nambu et al., 1990). Similarly, ectopic expression of sim in the neuroectoderm transforms the entire CNS into midline cells (Nambu et al., 1991). However, here we suggest a further refinement of sim function and propose that sim commits cells to an MP4 neural precursor fate that is followed by a series of signaling events that act on these cells to generate a diverse group of midline neuronal precursors and glia. This concept extends the notion of master regulator to posit a specific function for sim in initiating MP4 fate while subsequently working combinatorially with other transcription factors to control midline cell type-specific gene expression (Ma et al., 2000).

\section{$w g$, s/p1/2 and $h h$ establish a midline anterior neural precursor domain}

The midline cells initially appear morphologically and molecularly uniform, as characterized by the expression of $\operatorname{sim}$ in all mesectodermal cells. In our model, sim initially commits mesectodermal cells to an MP4 neural precursor fate (Fig. 8A). This is followed by $w g$ signaling that establishes an anterior domain in which cells are committed to an MP1 fate (Fig. 8B). This is mediated by activation of $s l p 1 / 2$ expression in anterior cells. Signaling by $h h$ also maintains a distinct $\operatorname{slp} 1 / 2$ anterior-posterior boundary. One important aspect of $s l p 1 / 2$ function is the repression of $e n$ in the anterior region, as experimentally inducing en in wildtype anterior cells disrupts MP3 and MP1 neuronal development. In this sense, slp1/2 play a role in midline neural precursor development that is conceptually similar to that of runt in $\mathrm{MG}$ development (Watson et al., 2011). The major function of runt in MG is to repress en expression in ensheathing glia (AMG) and ensure that AMG do not become $\mathrm{en}^{+}$non-ensheathing glia (PMG).

\section{hh signaling specifies MP3 identity}

Both $h h$ mutant and misexpression/overexpression experiments indicate that $h h$ signaling is required for MP3 identity (Fig. 8C). The influence of $h h$ on MP3 identity occurs largely, if not completely, by $h h$ activation of $g s b / g s b-n$ expression. $h h$ is also required for expression of the bHLH factor L(1)sc in MPs, and both $h h$ and $l(1) s c$ mutants have similar proneural phenotypes with regard to the formation of MP4-6 and the MNB (Stagg et al., 2011). However, $l(1) s c$ does not play a proneural role in MP3, even though it is expressed in MP3 (Stagg et al., 2011). There are two interpretations of the $h h$ mutant results. In one scenario, MP3 fails to form and divide in an $h h$ mutant, and thus $h h$ plays an MP3 proneural role. Since MP3 formation is unaffected in $g s b / g s b-n$ and $l(1) s c$ mutants, the proneural function of $h h$ may act through direct activation of proneural target genes by the $h h$ pathway transcriptional effector $\mathrm{Ci}$, or it could be through indirect $\mathrm{Ci}$ activation of additional transcription factors. Another interpretation is that MP3 is transformed in an $h h$ mutant into an MP4-6-like cell, and MP4-6 fail to form. In this case, $h h$ would not be acting as an MP3 proneural gene.

It is important to note that $h h$ signaling is postulated to convert a group of about five cells to an MP3 fate (Fig. 8C). The selection of the single MP3 found in each segment is through Notch signaling (Fig. 8D) (Wheeler et al., 2008). In this manner, DeltaNotch lateral inhibition results in the appearance of a single MP3, while the remaining cells become AMG and PMG. However, the division of MP3 is dependent on $h h$, and not Notch, signaling, as both MP3 and MP1 divide and differentiate in Delta mutant embryos (Wheeler et al., 2008). When $h h$ signaling is activated in all midline cells in either ptc mutants or by $h h$ pathway gene overexpression, cells destined to become MP1 instead become MP3. This suggests that, in wild-type embryos, the Hh morphogen is insufficiently active to direct the anteriormost cells to become MP3 even though these cells have the intrinsic ability to become MP3 if $h h$ signaling is activated. Future studies will address the pathway by which $h h$ controls MP3 formation, how MP1 is specified, and how $h h$ signaling is inhibited in the cells that give rise to MP1.

\section{gsb/gsb-n direct MP3 cell fate}

$g s b$ and $g s b-n$ are targets of $h h$ signaling and act to specify MP3 cell fate. Although not required for MP3 delamination or division, gsb/gsb- $n$ mutant embryos did show a delay in the timing of MP3 division, which can be considered an aspect of cell fate. Both genes 
A

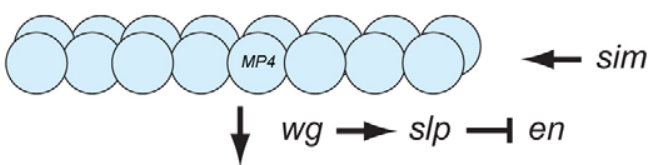

B

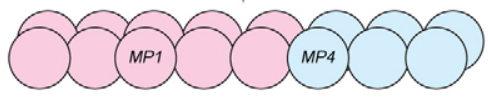

$h h \rightarrow$ gsb/gsb- $n$

C

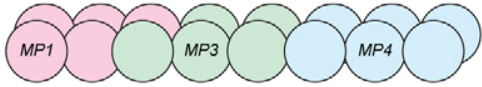

Notch

D

E

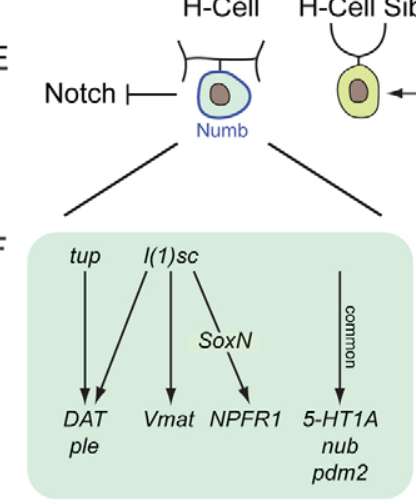

Fig. 8. Major steps in MP3 and H-cell development. A single segment is shown. (A) sim commits mesectodermal cells to an MP4 fate. (B) $w g$ signaling activates s/p 1/2 expression in the anterior region, which represses en and commits cells to an MP1 fate (pink). (C) $h h$ signaling directs a group of anterior cells to an MP3 fate (green) by activating expression of gsb/gsb- $n$. (D) Notch signaling selects one cell in the MP3 cluster to become MP3. (E) H-cell and H-cell sib fates are determined by Notch signaling and asymmetric localization of Numb. gsb/gsb- $n$ activate expression of $I(1) s c$ and tup in the H-cell. (F) $I(1) s c$ and tup control $\mathrm{H}$-cell-specific gene expression and differentiation. Genes expressed in common between the $\mathrm{H}$-cell and $\mathrm{H}$-cell sib are regulated by a different pathway.

are expressed in MP3 and each plays a role in MP3 cell fate specification. Embryos homozygous mutant for $g s b$ show defects in MP3 development, but these are less severe than in $g s b g s b-n$ double-mutant embryos, indicating functional roles for both genes. One function of $g s b$ is to activate expression of $g s b-n$ in MP3, indicating that these genes might function in a hierarchical manner. The role of $g s b-n$ was reinforced from misexpression experiments, in which MP1 was transformed into MP3.

Upon division of MP3, the two progeny, i.e. the H-cell and $\mathrm{H}-$ cells sib, acquire their distinct identities due to Numb asymmetric localization and Notch signaling (Fig. 8E) (Wheeler et al., 2008). Whereas H-cell sib differentiation is dependent on Notch signaling, $\mathrm{H}$-cell differentiation is largely dependent on the L(1)sc and Tup transcription factors (Fig. 8F). Genetically, gsb/gsb- $n$ function is required for expression of $l(1) s c$ and tup, linking cell fate to differentiation. Interestingly, $l(1) s c$ also controls mVUM-specific gene expression in addition to $\mathrm{H}$-cell-specific gene expression. This raises the question of how the same transcription factor, L(1)sc, controls two distinct developmental programs. Since the $\mathrm{H}$-cell and mVUMs differ in their MP precursors, one possibility is that Gsb/Gsb-n combinatorially interact with L(1)sc to control H-cell transcription and differentiation, whereas $\mathrm{L}(1) \mathrm{sc}$ interacts with an unknown MP4-6 cell fate factor to control mVUM transcription and differentiation.

\section{Acknowledgements}

We thank Chris Doe, Florence Maschat, Bruno Marie, Jim Skeath and Andrew Tomlinson for antibodies and Drosophila strains; Scott Wheeler for advice; Tony Perdue for assistance with microscopy; Frank Conlon for comments on the manuscript; the Developmental Studies Hybridoma Bank for monoclonal antibodies; and the Bloomington Drosophila Stock Center for Drosophila strains.

\section{Funding}

This work was supported by National Institutes of Health $(\mathrm{NIH})$ grants [R01 NS64264 (NINDS) and R37 RD25251 (NICHD) to S.T.C.]; a University of North Carolina Developmental Biology NIH training grant fellowship to J.D.W.; and a National Research Service Award (NRSA) postdoctoral fellowship to J.D.W. Deposited in PMC for release after 12 months.

\section{Competing interests statement}

The authors declare no competing financial interests.

\section{Supplementary material}

Supplementary material available online at

http://dev.biologists.org/lookup/suppl/doi:10.1242/dev.079525/-/DC1

\section{References}

Bate, C. M. and Grunewald, E. B. (1981). Embryogenesis of an insect nervous system II: a second class of neuron precursor cells and the origin of the intersegmental connectives. J. Embryol. Exp. Morphol. 61, 317-330.

Bhat, K. M., van Beers, E. H. and Bhat, P. (2000). Sloppy paired acts as the downstream target of wingless in the Drosophila CNS and interaction between sloppy paired and gooseberry inhibits sloppy paired during neurogenesis. Development 127, 655-665.

Bossing, T. and Brand, A. H. (2006). Determination of cell fate along the anteroposterior axis of the Drosophila ventral midline. Development 133, 10011012.

Brand, A. (1995). GFP in Drosophila. Trends Genet. 11, 324-325.

Broihier, H. T. and Skeath, J. B. (2002). Drosophila homeodomain protein dHb9 directs neuronal fate via crossrepressive and cell-nonautonomous mechanisms. Neuron 35, 39-50

Cadigan, K. M., Grossniklaus, U. and Gehring, W. J. (1994). Functional redundancy: the respective roles of the two sloppy paired genes in Drosophila segmentation. Proc. Natl. Acad. Sci. USA 91, 6324-6328.

Colomb, S., Joly, W., Bonneaud, N. and Maschat, F. (2008). A concerted action of Engrailed and Gooseberry-Neuro in neuroblast 6-4 is triggering the formation of embryonic posterior commissure bundles. PLOS ONE 3, e2197.

Duman-Scheel, M., Li, X., Orlov, I., Noll, M. and Patel, N. H. (1997). Genetic separation of the neural and cuticular patterning functions of gooseberry. Development 124, 2855-2865.

Grossniklaus, U., Pearson, R. K. and Gehring, W. J. (1992). The Drosophila sloppy paired locus encodes two proteins involved in segmentation that show homology to mammalian transcription factors. Genes Dev. 6, 1030-1051.

Guillén, I., Mullor, J. L., Capdevila, J., Sánchez-Herrero, E., Morata, G. and Guerrero, I. (1995). The function of engrailed and the specification of Drosophila wing pattern. Development 121, 3447-3456.

Gutjahr, T., Patel, N. H., Li, X., Goodman, C. S. and Noll, M. (1993). Analysis of the gooseberry locus in Drosophila embryos: gooseberry determines the cuticular pattern and activates gooseberry neuro. Development 118, 21-31.

Hatini, V. and DiNardo, S. (2001). Divide and conquer: pattern formation in Drosophila embryonic epidermis. Trends Genet. 17, 574-579.

Ingham, P. W. and McMahon, A. P. (2001). Hedgehog signaling in animal development: paradigms and principles. Genes Dev. 15, 3059-3087.

Kearney, J. B., Wheeler, S. R., Estes, P., Parente, B. and Crews, S. T. (2004). Gene expression profiling of the developing Drosophila CNS midline cells. Dev. Biol. 275, 473-492.

Kosman, D., Small, S. and Reinitz, J. (1998). Rapid preparation of a panel of polyclonal antibodies to Drosophila segmentation proteins. Dev. Genes Evol. 208, 290-294

Larsen, C. W., Hirst, E., Alexandre, C. and Vincent, J. P. (2003). Segment boundary formation in Drosophila embryos. Development 130, 5625-5635. 
Lee, J. J., von Kessler, D. P., Parks, S. and Beachy, P. A. (1992). Secretion and localized transcription suggest a role in positional signaling for products of the segmentation gene hedgehog. Cell 71, 33-50.

Lundell, M. J. and Hirsh, J. (1994). Temporal and spatial development of serotonin and dopamine neurons in the Drosophila CNS. Dev. Biol. 165, 385396.

Ma, Y., Certel, K., Gao, Y., Niemitz, E., Mosher, J., Mukherjee, A., Mutsuddi, M., Huseinovic, N., Crews, S. T., Johnson, W. A. et al. (2000). Functional interactions between Drosophila bHLH/PAS, Sox, and POU transcription factors regulate CNS midline expression of the slit gene. J. Neurosci. 20, 4596-4605.

Marie, B., Pym, E., Bergquist, S. and Davis, G. W. (2010). Synaptic homeostasis is consolidated by the cell fate gene gooseberry, a Drosophila pax3/7 homolog. J. Neurosci. 30, 8071-8082

Nambu, J. R., Franks, R. G., Hu, S. and Crews, S. T. (1990). The single-minded gene of Drosophila is required for the expression of genes important for the development of CNS midline cells. Cell 63, 63-75

Nambu, J. R., Lewis, J. O., Wharton, K. A., Jr and Crews, S. T. (1991). The Drosophila single-minded gene encodes a helix-loop-helix protein that acts as a master regulator of CNS midline development. Cell 67, 1157-1167.

Nusslein-Volhard, C., Wieschaus, E. and Kluding, H. (1984). Mutations affecting the pattern of the larval cuticle in Drosophila melanogaster. III. Zygotic loci on the second chromosome. Dev. Genes Evol. 193, 267-282.

Patel, N. H., Martin-Blanco, E., Coleman, K. G., Poole, S. J., Ellis, M. C., Kornberg, T. B. and Goodman, C. S. (1989). Expression of engrailed proteins in arthropods, annelids, and chordates. Cell 58, 955-968.

Porter, J. A., Ekker, S. C., Park, W. J., von Kessler, D. P., Young, K. E., Chen, C. H., Ma, Y., Woods, A. S., Cotter, R. J., Koonin, E. V. et al. (1996). Hedgehog patterning activity: role of a lipophilic modification mediated by the carboxyterminal autoprocessing domain. Cell 86, 21-34.

Robinow, S. and White, K. (1991). Characterization and spatial distribution of the ELAV protein during Drosophila melanogaster development. J. Neurobiol. 22, 443-461.
Sato, A. and Tomlinson, A. (2007). Dorsal-ventral midline signaling in the developing Drosophila eye. Development 134, 659-667.

Skeath, J. B. and Thor, S. (2003). Genetic control of Drosophila nerve cord development. Curr. Opin. Neurobiol. 13, 8-15.

Stagg, S. B., Guardiola, A. R. and Crews, S. T. (2011). Dual role for Drosophila lethal of scute in CNS midline precursor formation and dopaminergic neuron and motoneuron cell fate. Development 138, 2171-2183.

Thor, S. and Thomas, J. B. (1997). The Drosophila islet gene governs axon pathfinding and neurotransmitter identity. Neuron 18, 397-409.

Tio, M., Toh, J., Fang, W., Blanco, J. and Udolph, G. (2011). Asymmetric cell division and Notch signaling specify dopaminergic neurons in Drosophila. PLoS ONE 6, e26879.

Tran, K. D. and Doe, C. Q. (2008). Pdm and Castor close successive temporal identity windows in the NB3-1 lineage. Development 135, 3491-3499.

Vogler, G. and Urban, J. (2008). The transcription factor Zfh1 is involved in the regulation of neuropeptide expression and growth of larval neuromuscular junctions in Drosophila melanogaster. Dev. Biol. 319, 78-85.

Watson, J. D., Wheeler, S. R., Stagg, S. B. and Crews, S. T. (2011). Drosophila hedgehog signaling and engrailed-runt mutual repression direct midline glia to alternative ensheathing and non-ensheathing fates. Development 138, 12851295.

Wheeler, S. R., Kearney, J. B., Guardiola, A. R. and Crews, S. T. (2006). Singlecell mapping of neural and glial gene expression in the developing Drosophila CNS midline cells. Dev. Biol. 294, 509-524.

Wheeler, S. R., Stagg, S. B. and Crews, S. T. (2008). Multiple Notch signaling events control Drosophila CNS midline neurogenesis, gliogenesis and neuronal identity. Development 135, 3071-3079

Wheeler, S. R., Stagg, S. B. and Crews, S. T. (2009). MidExDB: a database of Drosophila CNS midline cell gene expression. BMC Dev. Biol. 9, 56.

Xiao, H., Hrdlicka, L. A. and Nambu, J. R. (1996). Alternate functions of the single-minded and rhomboid genes in development of the Drosophila ventral neuroectoderm. Mech. Dev. 58, 65-74. 